\title{
Reflexões sobre o não-escolar na escola e para além dela*
}

\author{
José Augusto Palhares \\ Universidade do Minho, Portugal
}

\section{Resumo}

Admitindo-se que a escola pública está em transformação, particularmente no que respeita à (re)definição das suas funções sociais e à sua expressão na estruturação do quotidiano das crianças e dos jovens, partimos para esta reflexão alimentados pela convicção de que é possível compreendê-la pela deambulação crítica entre as suas fronteiras e ao mesmo tempo estabelecer pistas de análise sobre as relações que esta instituição estabelece com outras instâncias educativas. A implementação de medidas políticas como a "escola a tempo inteiro" surge neste texto como a alavanca reflexiva para se pensar as possibilidades educativas que se esboçam entre o escolar e o não-escolar, tanto nos espaços e tempos escolares como para além deles. Não deixaremos também de problematizar a crescente centralidade da cultura escolar na construção e na definição de percursos, estratégias e experiências de educação (não-formais e informais) nos distintos quadros de vida dos alunos.

Palavras-chave

Educação escolar e educação não-escolar (não-formal e informal); Percursos educativos; Escola a tempo inteiro; Periferias educativas

\section{Introdução}

O desafio que se coloca ao investigador em educação, quando se propõe compreender a escola na actualidade, materializa-se na procura de 
um sentido de análise que lhe permita ultrapassar o emaranhado de representações e lugares-comuns educacionais que se foram cristalizando sobre aquela instituição social. Igualmente a sua condição de sujeito histórico, marcada por uma experiência prolongada de escolarização, tende a introduzir alguma subjectividade na selecção dos objectos de análise, surgindo estes, muitas vezes, de terrenos mais próximos e reconhecíveis, e nesta óptica é o próprio investigador a emaranhar-se na construção da realidade, nem sempre daqui resultando o melhor ângulo de focagem. Esta advertência, em jeito de vigilância crítica, ajusta-se à nossa preocupação em abordar as mutações ocorridas na escola pública portuguesa nos últimos tempos, na medida em que esta reflexão irá deambular por entre as fronteiras analíticas (clássicas) da escola como objecto, convocando para esse efeito alguns domínios que fomos observando na dupla condição de (co-)actor-investigador, de modo a ilustrar que a escola portuguesa, tal como em outros contextos europeus, está em transformação não só quanto à sua forma mas também quanto à sua natureza (cf. Dubet \& Martucelli, 1996).

Os dados empíricos que convocarmos mais para o final deste texto pretendem apenas dar suporte a algumas pistas de investigação equacionadas e a aprofundar futuramente, não surgindo com a espessura interpretativa que certamente as aludidas mutações carecem, designadamente aquelas que vieram alterar uma certa relação de forças entre as lógicas curriculares tradicionais e um vasto leque de saberes e de aprendizagens que se dispunham em complementaridade no quotidiano extra-escolar. A implementação da "escola a tempo inteiro"1, tanto no que respeita ao alargamento do horário das escolas do $1^{\circ}$ ciclo, como no que concerne à ocupação plena dos tempos escolares, afigura-se uma peça importante na renovação do debate sobre o papel contemporâneo da escola e suas correlativas funções sociais. Igualmente do ponto de vista teórico estas medidas políticas abrem espaço para se discutir sociologicamente o próprio universo educativo, considerado na sua versão mais ampla e não meramente adstrito aos contornos oficiais da cultura escolar. Mas estas transformações deixam bem patente o diagnóstico de Correia \& Matos (2001) quando falam de um "novo escolocentrismo", repercutido, em nosso entender, na (re)definição de novas temporalidades intra e extra-escolares e de novos desafios e reposicionamentos dos diversos actores educativos. A escola 
pública que hoje se esboça é, assim, uma instituição mais ampla, diversa e contraditória: porque se estendeu e prolongou o quotidiano educativo de crianças e jovens, quer em tempo de permanência no seu interior, quer nos ajustamentos que isto implicou para a frequência tardia de outras actividades fora da escola; porque acolheu novos públicos, construiu um catálogo de formações para além da oferta clássica e fomentou o desenvolvimento de actividades extra-lectivas (e.g. projectos, clubes, etc.) com vista ao suposto enriquecimento curricular dos alunos; e porque, não obstante o "declínio do [seu] programa institucional" (Dubet, 2002), insistiu na velha "forma escolar" (cf. Vincent, Lahire \& Thin, 1994), como se as suas fronteiras com a comunidade e com o saber fossem ainda inquestionáveis e como se a ideia de futuro alimentada pelo projecto da modernidade não se estivesse também a diluir na própria escola.

Se esta renovada centralidade da escola pode ser entendida como uma forma de se atenuar a erosão da sua legitimidade social, não será menos verdade admitirmos que os efeitos do seu alargamento no quotidiano enfatizam as experiências educativas escolocentradas de crianças e de jovens, assim como condicionam as possibilidades de outros contextos e projectos se desenvolverem no âmbito da almejada cidade educativa. Face a este cenário, parece-nos cada vez mais claro que a rotulagem da escola como a instituição de "educação formal" está em perda de significado, pois nos espaços e tempos escolares coexistem processos e actividades de natureza não-formal e informal, dinamizados internamente, e lógicas, racionalidades e projectos de vida ancorados externamente em investimentos educativos (nãoformais e informais), de potencial mais-valia no desempenho escolar dos alunos. Não se tendo propriamente concretizado a "desformalização das instituições" (e concretamente da educação formal), como auguravam alguns autores na década de 1970 (cf. entre outros, Faure et al., 1973; Quintana Cabanas, 1976), contudo, outras percepções revelaram-se porventura mais assertivas quando apontaram para a tendência de formalização do informal (Quintana Cabanas, 1976; Canário, 2006) e o cenário da formalização do nãoformal (Lima: 2006). Partilhando o sentido conferido à escola como "entreposto cultural" (Torres, 2008), justifica-se, por conseguinte, não ignorarmos os desenvolvimentos das periferias educativas da escola, mais a mais por estas se afigurarem, porventura, como contextos de aprendizagens 
significativas, ou mesmo como possibilidades e/ou experiências de diversificação e enriquecimento cultural, cujo valor não é sociologicamente irrelevante nos espaços e tempos transaccionais da instituição escolar.

\section{Quarenta anos na sombra da crise da escola}

O curso subsequente desta reflexão evidencia uma perspectiva de análise que admite a possibilidade de "repensar o escolar a partir do nãoescolar" (Canário, 2002: 150), não se refutando liminarmente os eventuais efeitos transformadores provindos de "referentes externos", muito embora tal cenário nos pareça improvável face aos desenvolvimentos recentes da escola pública. Se a ruptura com a lógica convencional da escola pode ser projectada pela "contaminação" fecunda de ideias e práticas inspiradas no não-escolar (Id., Ibid.), no entanto, aquilo que nos é dado a observar é uma tendência para a consolidação e reforço do núcleo central do currículo, atribuindo-se às modalidades extra-curriculares um lugar secundário no processo educativo. Mesmo a suposta conflitualidade (latente) no que concerne "à delimitação das fronteiras entre o escolar e o não-escolar" (Correia, 1998: 132) parece não constituir um factor desencadeador de uma ruptura conceptual de escola, até porque tal desiderato tende a esbarrar com as predisposições das famílias e dos próprios alunos, que há muito se encarregaram de situar a escola num plano simbólico e de referência. Basta pensarmos que os investimentos diferenciais no não-escolar têm constituído uma peça importante na construção de percursos escolares distintivos e de reprodução social e cultural (La Belle, 1982), sem que com isso se dessignificasse a escola como instituição central na educação e socialização. O não-escolar, nas sociedades ocidentais, tem sido marcado sobretudo pelas funções de complemento e (nalguns casos) de suplemento à educação escolar, não obstante as propostas de redefinição do campo educativo e os discursos sempre renovados de "crise" da escola. Em grande medida isto deve-se à centralidade conferida aos resultados e não tanto ao processo educativo, à excelência escolar e em menor escala ao seu papel no aprofundamento da cidadania democrática, enfim, ao paradigma de organização social subjugado às lógicas da economia e da competitividade. Aliás, como seguidamente veremos, o não-formal se por um lado emerge associado à incapacidade da escola em cumprir as promessas da modernidade, tendo sido ensaiado como 
alternativa preferencial em países e contextos desfavorecidos, por outro lado, hoje ressurge com uma aura renovada capaz de ajudar a resolver os problemas de educação e formação nos países ocidentais, quando nalguns países africanos, por exemplo, por ter sido uma educação de segunda, distinta da valorizada educação formal "branca", assume uma conotação negativa, "decididamente impopular" (Rogers, 2004: 4)2.

As últimas quatro décadas foram marcadas no campo da educação por um acumular de propostas reflexivas de inegável valor, de onde se destacam aquelas que procuraram situar a escola no amplo quadro da vida social e particularmente aquelas que esboçaram a articulação desta instituição com outras modalidades de educação e formação. Apesar do escrutínio e da reactualização permanente do lugar da escola no quotidiano das pessoas, o certo é que esta instituição nunca se desenraizou do centro do processo educativo, como se o esboço de Paulston (1972: ix) para a construção genérica de um qualquer sistema educativo nacional fosse premonitório quanto às relações e posições entre os vários subsistemas: a escola surgia no centro e no alinhamento concêntrico imediato o autor dispôs a educação não-formal, a educação informal e a educação internacional. A ele se deve a ideia da educação não-formal como "periferia" e num certo sentido a atribuição de um papel utilitário como um complemento, um suplemento ou uma alternativa aos programas de educação formal. Como a seguir veremos, houve neste período a preocupação em delimitar conceptualmente a educação numa perspectiva educacional integrada (La Belle \& Verhine, 1975a) e na ambiência da educação permanente (cf. Brembeck, 1976; La Belle, 1982), muito embora tal esforço nunca se alheasse do diagnóstico socialmente construído de "crise" de escola.

\subsection{Da crise da escola à procura de alternativas educativas}

O relatório The World Educational Crisis apresentado por Philip $\mathrm{H}$. Coombs, em 1967, remetia o diagnóstico da crise essencialmente para o quadro dos sistemas formais de ensino (cf. Bhola, 1983), paradoxalmente numa década em que se atingiam números sem precedentes de taxas de escolarização. A ausência de indicadores que consubstanciassem uma efectiva transformação social teve como corolário o enfraquecimento das expectativas depositadas no evoluir da "espiral da 'revolução das 
esperanças'" (Husén, 1982: 48; aspas no original). Diante da frieza dos dados que cada vez mais evidenciava a impossibilidade de concretização do "sonho" universal da escolarização de massas (cf. Bhola, 1983), não se estranha, por isso, que no mesmo trabalho onde se diagnosticava a "crise mundial de educação" encontrássemos, nas palavras posteriores de Coombs (1985: 26; aspas no original), "um capítulo provocador e profético que chamava a atenção sobre a importância futura do que o relatório denominou 'educação não-formal'".

No referido relatório de Coombs (1968: 203) chamava-se a atenção para a existência de um "sistema paralelo" de educação, perspectivado como um "conjunto anárquico de actividades não-escolares de educação e de formação [como] um importante complemento do ensino escolar, um e outro ajustando-se para constituir o esforço máximo consentido por um país para instruir a sua população". Face a uma educação formal estruturada e coerente justapunha-se uma educação não-formal algo dispersa por um sem-número de actividades, com objectivos e clientelas mal definidos, por isso mesmo não subjugada a uma lógica agregadora de um qualquer sistema.

A educação não-formal, que mais tarde iria merecer uma atenção particular de Coombs e colaboradores (cf., Coombs, 1973; Coombs, Prosser, \& Ahmed, 1973; Coombs \& Ahmed, 1975), mesmo subalternizada em relação à educação formal poderia, contudo, vir a assumir um papel de relevo na economia dos processos educativos, já que se constituía como "uma contribuição rápida e substancial no progresso dos indivíduos e da nação" (Coombs, 1968: 203). Apesar de considerar esta noção ampla, o autor não ignorou uma multiplicidade de factores de inegável valor educativo que tendem a passar despercebidos no quotidiano e que configuram aquilo que mais tarde se veio a designar de "educação informal": "refira-se nesta perspectiva os livros, jornais e revistas; o cinema e as emissões de rádio e televisão; enfim e sobretudo a influência educativa da vida familiar" (Ibid.: 205).

O léxico educativo contava, a partir de então, com as designações de educação não-formal e educação informal, muito embora sendo ambas usadas indistintamente, segundo Trilla Bernet (1998: 18), para "designar o amplíssimo e heterogéneo leque de processos educativos não-escolares ou situados à margem do sistema de ensino oficial". Não se pense, porém, que 
pelo simples facto de se proceder à classificação dos fenómenos educativos situados ora dentro ora fora do marco institucional da escola se estaria, consequentemente, a reinventar o campo educativo. Pelo contrário, e no que à educação não-formal diz respeito, vários autores sublinharam que sob a abrangência desta nova expressão residiam antigas preocupações educativas (cf., entre outros, La Belle \& Verhine, 1975a; Bhola, 1983; Radcliffe \& Colletta, 1989), sendo possível constatar historicamente inúmeros trabalhos alocáveis nesta categoria (como o comprovou Paulston, 1972), não obstante se encontrarem dispersos por uma grande variedade de temáticas e problemáticas similares, já para não falar nos antecedentes semânticos que, de acordo com Rogers (2004: 71 e segs.), se encontram ocasionalmente desde 1958 ("the nonformal educational enterprise", noção atribuída a Clark \& Sloan, 1958; "nonformal educational system", de autoria de Miles, 1964; e "nonformal education", da pertença de King, 1967) ${ }^{3}$. Como destacam Radcliffe \& Colletta (1989: 1838), "a novidade é a recente redescoberta da educação não-formal por parte dos planificadores do desenvolvimento e os novos valores atribuídos à sua contribuição no desenvolvimento dos recursos humanos". Aliás, na introdução de uma das obras mais referenciadas a propósito da clarificação conceptual dos três modos educacionais (cf. Coombs \& Ahmed, 1975) é o próprio Phillip Coombs a reconhecer não estarmos em presença de um fenómeno recente, mas que a educação não-formal tinha constituído, até então, um objecto pouco estudado sistematicamente. Tendo ou não subjacentes imperativos políticos, sociais e económicos diversos, a designação alcançou alguma popularidade investigativa nas décadas de setenta e oitenta, apesar do declínio observado na produção académica na década de noventa e nos primeiros anos do século XXI (cf. Palhares, 2007). Conquanto a actualidade não seja pródiga em trabalhos de fôlego neste subcampo educativo (excepção feita aos trabalhos de Poizat, 2003 e Rogers, 2004), contudo nos anos 2000 tem-se assistido à (re)descoberta da educação não-formal (e da educação informal), em grande medida pela sua colagem à retórica inerente ao paradigma da aprendizagem ao longo da vida (cf. Rogers, 2004). Mas também interessa aqui referir que a naturalização da ideia de uma educação não-formal se fez, de forma considerável, à custa da erosão sofrida pela educação formal, muito por culpa da crise, real ou virtual, e, de modo particular, por todos aqueles trabalhos que ao procurarem avolumar o 
património investigativo da educação não-formal não se coibiram em apontar as fraquezas institucionais do projecto de escolarização de massas e, em contrapartida, vislumbraram nessa configuração educativa emergente a fórmula para a consecução dos objectivos de desenvolvimento imediatos (cf. La Belle \& Verhine, 1975b).

\subsection{A educação (escolar e não-escolar) na cidade educativa}

Mas se há razões históricas e sociológicas que nos levam a não considerar aleatório o surgimento da educação não-formal neste período, tão pouco podemos ignorar a influência que nele teve a apologia do "ideal de educação permanente" (Lima, 2003: 129) perfilhado pela UNESCO a partir de meados dos anos sessenta e mais tarde consagrado pela publicação do relatório da Comissão Internacional para o Desenvolvimento da Educação, sob o título Apprendre à être (cf. Faure et al., 1973). Este trabalho procurava dar seguimento à ideia de que educação e aprendizagem nem recobriam o mesmo significado, nem se circunscreviam aos mesmos espaços-tempo da actividade humana e muito menos se esgotavam no curto ciclo de vida que uma pessoa normalmente destina ao cumprimento da escolaridade obrigatória4. E uma das propostas formuladas neste sentido passava pela "desformalização das instituições" de educação, o que para os autores significava retirar o monopólio educativo à escola, disseminá-lo por outros contextos de aprendizagem, reconhecendo-se, por conseguinte, que esta também seria possível nos diversos sítios da actividade quotidiana e, mais ainda, com o recurso a modalidades (educativas) extra-escolares. Tal como sublinhavam os autores, "todas as vias — formais e não-formais, intrainstitucionais e extra-institucionais - poderiam ser admitidas em princípio como igualmente válidas" (Faure et al., 1973: 270).

Tomando a noção de educação permanente 5 como fulcral na construção da cidade educativa, a perspectiva da educação que então emerge sustenta uma visão do ser humano como ser inacabado, cuja realização se concretizaria pela aprendizagem constante, ao longo da vida, independentemente da idade, e no decurso das múltiplas e diversas experiências de vida das pessoas. Enquanto este projecto não se concretizasse, o diagnóstico avançado pela Comissão Faure parecia querer convergir para um cenário congruente com a evolução esperada para a 
educação escolar e para a educação extra-escolar: "sendo já certo que o papel das instituições escolares é cada vez mais importante em valor absoluto, o seu papel relativo, comparado com outros meios educativos e outras formas de comunicação entre gerações, não cresce, pelo contrário, na realidade tende a diminuir" (Id.: 148).

Em boa verdade, se num primeiro momento somos levados a concordar com esta tendência, tendo em conta, nomeadamente, que "a invasão da escola por outras instâncias de difusão de conhecimentos" (Dandurand \& Ollivier, 1991: 4) teve implicações ao nível da sua legitimidade social, num momento posterior, a suposta perda de importância relativa da instituição escolar face a outras instâncias educativas parece, contrariamente, esbarrar num crescente acréscimo de responsabilização social e num renovado compromisso com os agentes da actividade económica.

O curso da história também se encarregou de desmentir aquele prognóstico quando aplicado à realidade dos países periféricos, para os quais se auguravam alternativas de carácter não-formal. Manzoor Ahmed considerou inclusivamente prematura a aludida ideia da perda de importância da escola apontada no relatório Faure, acrescentando que o optimismo depositado na educação não-formal para corresponder às necessidades de desenvolvimento tinha dado lugar, no início da década de oitenta, a um certo desencanto, já que "seria imprudente colocar muitas esperanças na educação não-formal" (Ahmed, 1983: 38). Mesmo nos países de capitalismo avançado, as mutações no campo económico colocaram na ordem do dia o papel central da escola na promoção da excelência, da eficácia, da eficiência, da competitividade, da produtividade, entre outros aspectos da racionalidade económica (cf. Afonso, 1998), quando se começaram a acentuar as tensões e os desequilíbrios não reguláveis pelas estruturas e pelas lógicas do mercado.

Não se tendo propriamente assistido à tendência de "desformalização" (e à "dessacralização") da escola, é, no entanto, inegável que se caminhou para a "diversificação" de contextos e de processos de cariz educativo. Num certo sentido, a perda de fulgor do modelo de socialização que vigorou na modernidade, associada à pulverização das experiências nos vários contextos e sítios do quotidiano (cf. Palhares, 2008), faz-nos pensar, na esteira de Touraine (1998), que de facto há muito se assiste a um movimento 
de desintitucionalização social (ou o declínio do "programa institucional", de que nos fala Dubet, 2002), e muito particularmente da escola. Entretanto, aguça-se a nossa curiosidade sociológica quando constatamos que as condições sociais e laborais das famílias têm vindo a acentuar o recurso à institucionalização quotidiana de crianças e de jovens, cujas respostas sociais se diversificam, seja no âmbito da organização escolar, seja em contextos periféricos de natureza não-escolar.

\subsection{A educação não é neutra: contextos culturais e aprendizagens significativas}

Outros autores deram o seu contributo para o desenvolvimento de uma atmosfera crítica em relação ao papel da escola na reprodução das estruturas de poder e de conhecimento nas sociedades capitalistas, ora acentuando o diagnóstico da crise da educação, ora inspirando a procura de alternativas à educação escolar, ora ainda procurando sedimentar a ideia de uma educação significativa enraizada nos sentidos educativos que se entrelaçam no quotidiano das pessoas. Por exemplo, as obras clássicas de Bourdieu \& Passeron (s/d.; 1990) revestem-se de um potencial heurístico não despiciendo quando se investe na compreensão da problemática da educação não-escolar, eventualmente com maior acuidade no que à educação informal, ou educação difusa, ou "incidental learning" diz respeito (cf., entre outros, respectivamente, Pain, 1990; Trilla Bernet, 1998; Grandstaff, 1976). A noção de capital cultural, cuja posse diferenciada pelos alunos permite a proximidade ou o afastamento em relação à cultura escolar e a consequente tradução em distintas probabilidades de sucesso nos percursos individuais de escolarização, sendo para aqueles autores resultado de um processo de interiorização subtilmente estruturado em contextos e processos exteriores à escola, não deixa indiferente o investigador sempre que se confronta com a multiplicidade de recursos educativos mobilizáveis e mobilizados na periferia da escola, acedidos pelas famílias para quem a organização escolar se revela educativamente incompleta. No fundo, obedecendo ou não a estratégias previamente delineadas, os alunos de origens sociais mais favorecidas constroem o seu habitus através da naturalização das disposições e experiências balizadas pelas suas estruturas de acção, sendo estas potenciadoras de um vasto repertório de modalidades 
extra-escolares, de práticas de refinamento do gosto por um determinado tipo de expressões artísticas e culturais (cf. Bourdieu, 1979), da sofisticação dos consumos e dos lazeres, das viagens e do turismo cultural, entre outro tipo de práticas distintivas ${ }^{6}$. As possibilidades educativas que aqui se vislumbram, mais do que um mero complemento ou suplemento à educação escolar representam uma matriz de aprendizagens significativas com evidentes vantagens na consolidação das trajectórias escolares e profissionais desses alunos.

O desafio de repensar a escola a partir do exterior, pelo menos do ponto de vista reflexivo, remete-nos de imediato para uma das obras centrais de Paulo Freire, Pedagogia do Oprimido, também ela surgida (1970) nos alvores do período de efervescência crítica que se estendeu à generalidade das estruturas sociais, não fugindo a escola à regra, sendo esta particularmente visada no que respeita à sua pretensa neutralidade $\mathrm{e}$ democraticidade. Não estranha, por isso, que Paulo Freire (1972: 193) tenha assumido como pressuposto básico o de que "a educação não pode ser neutra"7, o que significava denunciar a educação como "domesticação", quer dizer, a educação como um poderoso instrumento de alienação e controlo social, pois ao impor a mistificação do mundo impedia o sujeito da descoberta e da invenção do conhecimento. Consequentemente, o ponto nodal da sua crítica situou-se nos processos e nas relações pedagógicas que alimentam a "educação para a domesticação", na medida em que "os problemas de base da pedagogia não são estritamente pedagógicos, mas antes políticos e ideológicos" (Freire, 1976: 72).

Associada a esta constatação emerge uma das noções mais popularizadas do pensamento de Paulo Freire, designadamente a "educação bancária", a partir da qual se pretende ironicamente ilustrar o carácter "antidialógico" da relação educativa, em que, por um lado, ao aluno se reserva um lugar passivo - portanto objecto - da acção educativa, como se um mero recipiente de conhecimento se tratasse ${ }^{8}$; e por outro lado, o professor/o educador erige-se como o único detentor da realidade e como tal é investido da função de transmissão dos saberes que ele julgar pertinentes para a dócil plateia dos alunos/educandos. A ênfase que Freire coloca no diálogo é justamente para que se consiga transformar o sentido da relação pedagógica, ao aceitar-se, numa base de respeito mútuo, que ninguém é soberano no 
capítulo do saber, pois educadores e alunos partilham simultaneamente a condição de sujeito-objecto do conhecimento ao trabalharem uns com os outros.

Do legado freireano releva-se uma metodologia da acção pedagógica que granjeou um assinalável apreço na morfologia dos programas de educação não-formal, assim como implicitamente nos reconduz para a importância da relação do sujeito com o mundo que o rodeia, a partir da qual procura o sentido da transformação social pelas aprendizagens significativas do seu quotidiano. Dá-se, por conseguinte, relevo aos contextos e processos de experiência social, nos quais se partilha o conhecimento e se (re)descobre e compreende criticamente a realidade, o que pode constituir, particularmente para "os que não têm voz" (os oprimidos), uma possibilidade para o desenvolvimento da consciência de que a transformação social é possível, desde que os sujeitos se "conscientizem" que têm poder para o fazer, a partir do seu lugar no mundo.

\subsection{A desescolarização da sociedade}

Mas se a ambiência da época favoreceu a emergência de uma perspectiva holística da educação (global e permanente), não menos importante se revelou o aparecimento contemporâneo de propostas de desinstitucionalização da escola ainda mais radicais, subscritas, sobretudo, por Ivan Illich (1988) e secundadas por Everett Reimer (1976). Estes autores destacaram-se pela partilha da convicção "de que a maioria dos homens tem seu direito de aprender cortado pela obrigação de frequentar a escola" (Illich, 1988: 17).

A apologia da "desescolarização das sociedades escolarizadas" surge "como primeira fase dum programa mais geral de inversão das instituições" (Illich, 1973: 30), já que para o autor a escola estaria por detrás destas instituições e como tal funcionaria como estrutura reprodutora e sancionadora da sociedade capitalista (cf. Canário, 2005). A adopção de uma posição relativizadora das diversas experiências escolares tende a subestimar mesmo aquelas que constituíram para os indivíduos algo de positivo: "A maioria dos homens no mundo sabe que está irremediavelmente excluída dum ensino satisfatório. Outros, que passaram por uma 'boa' escola, sabem que sofreram 
prejuízos. E finalmente a maior parte daqueles que, duma certa maneira, tiveram algum proveito com a escola, sabem que não foi lá que aprenderam o que os ajudou no respectivo trabalho e também que a contribuição da escola para o êxito deles não resultou provavelmente do conteúdo do ensino" (Illich, 1973: 30; aspas no original).

Recusando liminarmente a procura de soluções para a "crise do ensino" baseadas em mais actividades escolares, a "inversão da estrutura institucional" emerge, pois, como o passo metodológico para se encontrarem, no seio da "convivialidade", as alternativas educacionais necessárias para se instituir o novo tipo de sociedade. Conquanto, as propostas avançadas por Illich para superar essa crise mais não são do que as idealizadas no seu projecto social de ensino livre e de autonomia na decisão quanto à formação a seguir.

Objectivando a criação de "teias de aprendizagem" (learning webs) qual prenúncio para a actual sociedade em rede! - para superar as representações e o modo de pensar escolarizados dos indivíduos, a nova configuração educativa apresentava-se, assim, não burocratizada e hierárquica, tal qual como "canais" que possibilitariam o acesso aos recursos ("coisas", "modelos", "colegas" e "adultos") de aprendizagem. Esta utopia pretendia, por conseguinte, libertar o ser humano da pressão (escolar) da aprendizagem e (re)ligar a sociedade ao ambiente pelo desenvolvimento de novas "relações educadoras interumanas" (Illich, 1976: 23).

Efectivamente, se o curso da história se encarregou de enfraquecer o vigor das propostas de Illich, remetendo-as, por assim dizer, para as prateleiras das extravagâncias educacionais, contudo, face ao escrutínio permanente a que tem sido submetida a educação escolar e ao inevitável diagnóstico (sempre renovado) de crise da escola, não raras vezes se assiste à sua recuperação como "uma solução que desvincule a educação das decisões políticas e culturais arbitrárias, apenas exequíveis em espaços e tempos isolados (e isoláveis) do mundo da vida" (Afonso, 2001: 29; itálico no original). Não se pense, porém, que a cristalização da ideia de um suposto esgotamento da escola apenas se alimenta das representações dos deserdados da escola, para quem esta constituiu uma "violência simbólica" (Bourdieu \& Passeron, s/d), ou das posições de determinados sectores sociais que sustentam, sobretudo por razões económicas, ser anacrónica a 
função do estado educador. Sendo a escola cada vez mais pressionada para cumprir novos mandatos educativos para além dos tradicionalmente atribuídos (cf., entre outros, Afonso, 2003; Nóvoa, 2006), o que contribui, na impossibilidade de os satisfazer, "para que os tempos e os espaços da escolarização sejam vividos como tempos e espaços permanentemente deficitários" (Correia \& Matos, 2001: 92), não se estranha, por isso, e correlativamente, ver a instituição escolar acossada pelo estigma da incompetência, favorecendo, a fortiori, os argumentos dos que sustentam a necessidade de se desenvolver um mercado (escolar) de oportunidades educativas e formativas alternativo à escola pública.

Contrariamente às intenções de Illich, não só não se caminhou rumo a uma sociedade desescolarizada como inclusivamente se acentuou o predomínio da escola e da educação escolar no panorama educativo, possivelmente configurando uma espécie de fenómeno de sobrescolarização do quotidiano das pessoas. E talvez, nesta óptica, tenhamos de Ihe reconhecer algum mérito, por ter sido dos primeiros a avançar com a ideia de pedagogização da sociedade (cf. Gadotti, 1995), para denunciar os efeitos da escolarização no sustento da crença do consumo ilimitado e, num certo sentido, da omnipresença da escola em todas as esferas da vida social. Porém, a realidade encarregou-se de não dar quaisquer hipóteses à "inversão das instituições", nem muito menos deu expressão ao domínio da "convivialidade" como matriz de interacção social. A tendência para a desintitucionalização como um dos traços mais característicos do quadro actual da modernidade (cf. Touraine, 1998), assim como a referida "pedagogização crescente da vida social" (cf. Afonso, 2001; 2003) — ou na sugestiva formulação de Basil Bernstein (2001: 13), de Sociedade Totalmente Pedagogisada -, reactualizam, com alguma ironia, alguns dos sentidos daquela utopia, muito embora não seja crível, a médio e a longo prazo, avançar com a hipótese do fim da escolarização. Porém a acumulação de indícios no campo educacional e do saber aconselham alguma prudência analítica e preditiva, concretamente no que se refere ao ensaio de algumas soluções ligadas ao uso das novas tecnologias da informação e da comunicação (por exemplo, e-learning, e-teaching, e outras cambiantes decorrentes do uso da internet e da exploração do ciberespaço), assim como à recuperação de algumas modalidades de ensino doméstico (home 
schooling), fenómeno em franca expansão nos Estados Unidos da América entre famílias numerosas e de classe média, e normalmente conotadas ideologicamente com os sectores políticos e religiosos mais conservadores (cf. Apple 2003; Torres Santomé, 2003).

Aceitando a realidade tal qual ela se impõe, dando expressão a lógicas de acção social de cariz mais reprodutor do que transformador, não espanta, por isso, que sobre as brechas de uma instituição em crise de legitimidade se voltem a modelar as formas de um "novo escolocentrismo" (Correia \& Matos, 2001). E se este nos situa no advento de novas ideologias educativas, então neste plano não podemos deixar de sublinhar, com Afonso (2001: 33), a disseminação da ideologia da aprendizagem ao longo da vida, que "numa aparente valorização da educação, pretende, em última instância, responsabilizar os indivíduos pela sua própria informação, formação e qualificação, em função de objectivos que pouco ou nada têm a ver com o seu desenvolvimento pessoal e intelectual numa dimensão crítica e emancipatória". A partir do momento em que se difunde na política e na economia a retórica do "lifelong learning/education", instala-se concomitantemente algum sincretismo no campo educativo, com particular acuidade na significação do conceito de educação, "sendo [este] progressivamente substituído pelo conceito de aprendizagem ao longo da vida e pelos seus derivados - qualificações, competências, habilidades" (Lima, 2009: 8). E do mesmo autor se acrescenta, que em vez de se "reconhecer a substantividade da vida ao longo da educação e das aprendizagens permanentes dos indivíduos", em seu lugar "o curso da vida [é] reduzido a uma interminável sucessão de formações e de aprendizagem úteis e eficazes" (Lima, 2007: 10). Assiste-se, igualmente, à recuperação acrítica dos modos educacionais formulados por Coombs \& Ahmed (1975), redescobrindo-se particularmente a educação não-formal como ferramenta utilizável no apoio ao crescimento económico e na promoção da cidadania activa (Rogers, 2004). Sintomático desta tendência é a apropriação conceptual dos três modos educacionais feita no Memorando sobre a Aprendizagem ao Longo da Vida, publicado em 2000 pela Comissão das Comunidades Europeias, surgindo agora o termo aprendizagem onde antes existia educação ${ }^{9}$. Aliás, a popularidade granjeada pela categorização de Coombs \& Ahmed (1975) há muito que se encontra em défice heurístico, 
sobretudo quando se constata a diversidade e a complexidade de contextos e de situações educativas. Espera-se que o debate sobre esta problemática recrudesça, até porque, esporadicamente, vêm sendo propostas algumas soluções para ultrapassar uma certa dificuldade em alocar os diversos fenómenos educativos naquela estrutura conceptual. A necessidade de se contextualizar a educação, consoante os sítios e os actores sociais e de se promover a coexistência entre as especificidades educativas, encontra, por exemplo, em La Belle (1981, 1982) e Rogers (2004) pistas interpretativas a não desprezar.

\section{A educação escolar para além da escola...e o seu regresso}

As lógicas de funcionamento e de organização das escolas públicas do $1^{\circ}$ ciclo cristalizaram durante muito tempo uma concepção de educação muito circunscrita a orientações curriculares formalmente definidas, à gestão dos espaços e tempos escolares mais dependente dos constrangimentos locais impostos por uma procura diferenciada de escolarização, à prevalência das aprendizagens nas áreas de conhecimento tidas como nucleares, ao ensaio, aqui e ali, de experiências lúdico-didácticas; enfim, e sem sermos redundantes, a uma concepção de educação muito presa à tradicional forma escolar (cf. Vincent, Lahire \& Thin, 1994). A sala de aula, mais do que a escola na sua globalidade, impôs-se como o contexto educativo de referência, o sítio onde se constroem e reconstroem as identidades, se atribuem os papéis institucionais e se exercem os respectivos ofícios escolares.

Se para muitas famílias a educação escolar sempre coexistiu com investimentos complementares de natureza não-escolar no percurso educativo dos seus filhos, não se colocando, por conseguinte, outros constrangimentos senão aqueles que decorrem da gestão (complexa) das rotinas pós-lectivas das crianças, para a maioria dos casos o principal aspecto crítico da escola pública residia justamente na estruturação dos tempos lectivos. Até à implementação das recentes políticas educativas para o $1^{\circ}$ ciclo (designadamente o alargamento do horário das escolas, a implementação do "regime normal", o desenvolvimento das actividades de enriquecimento curricular e de complemento curricular, entre outras ${ }^{10}$ ) os horários de funcionamento da escola pública, tanto em "regime duplo" como em "regime 
normal", para além de introduzirem condicionalismos na gestão das diversas disponibilidades familiares (sobretudo laborais e económicas), contribuíram grandemente para que se naturalizasse a ideia de que aos espaços e aos tempos de educação escolar deveriam suceder outros tempos e outros espaços, não necessariamente educativos, mas que assegurassem fundamentalmente a guarda das crianças em horário pós-escolar e, já agora, que garantissem o acompanhamento dos trabalhos escolares fora da escola ${ }^{11}$. À preocupação da escolha da escola, do professor e da turma, acrescentava-se também a preocupação com a selecção de uma instituição que cumprisse, pelo menos, aqueles dois requisitos.

Após alguma turbulência inicial nas escolas públicas do $1^{\circ}$ ciclo, decorrente da implementação e generalização da designada "escola a tempo inteiro", foi notória não só uma alteração significativa no quotidiano dos actores e das organizações escolares mas igualmente no reposicionamento da própria instituição escolar no capítulo das aprendizagens e das actividades culturais. A adopção gradual desta medida despoletou toda uma série de tensões com a comunidade educativa, sobretudo com aquelas instituições e contextos que tinham emergido pela capacidade de gerar "respostas sociais" nos espaços e nas oportunidades educativas não exploradas pela escola. Entre os que mais se ressentiram com estas mutações da escola pública encontramos os Centros de Actividades de Tempos Livres (CATL), popularmente reconhecidos pelo acrónimo ATL, tendo apenas subsistido aqueles que se conseguiram recompor nas franjas dos horários lectivos das escolas públicas e reorganizar a sua acção mais em torno de funções logísticas do que em torno de funções de carácter educativo. Se, por um lado, o seu apogeu na década precedente se inscreveu numa tendência de valorização dos domínios educativos não-escolares, por outro lado, também foi possível constatar nas suas múltiplas articulações com o espaço escolar um papel de complementaridade, uma espécie de assessoria educativa nãooficial, no fundo, o prolongamento do escolar para além da escola. Os CATL assumiram, assim, a continuidade do processo educativo, nomeadamente no aprofundamento e na sedimentação dos conteúdos adquiridos no horário escolar e na oferta de modalidades e actividades educativas em domínios pouco desenvolvidas, ou mesmo ignorados, pela escola pública. 
A estrutura de funcionamento da generalidade das escolas do $1^{\circ}$ ciclo vinha colocando às famílias o problema da compatibilidade horária e a consequente preocupação com a guarda das crianças nos tempos e nos períodos extra-lectivos. A procura de uma solução adequada aos mais variados quadros de vida implicava, quase sempre, a concretização de uma diversidade de arranjos entre os constrangimentos familiares e a oferta de contextos e de actividades de tempos livres existentes na comunidade. As desarticulações entre o funcionamento da escola e as necessidades das famílias consolidaram durante muito tempo uma espécie de fronteira imaginária entre o escolar e o não-escolar, com estatutos e valorações distintos, sobrepesando nesta relação a omnipresença quotidiana do primeiro. Mas a maior implicação prende-se, a nosso ver, com a capacidade diferencial que as famílias dispõem para o investimento nas actividades e aprendizagens não-formais e informais. Nada haveria a problematizar se a ampla literatura sociológica e educacional não tivesse já demonstrado, ad nauseam, a importância das aprendizagens e das experiências sociais externamente produzidas e que na escola tendem a repercutir-se positivamente no sucesso escolar dos alunos.

\begin{tabular}{|c|c|c|c|c|c|}
\hline HORAS & SEGUNDA & TERÇA & QUARTA & QUINTA & SEXTA \\
\hline 8:30 & Actividades Livres & Actividades Livres & \multicolumn{2}{|c|}{ Actividades Livres Actividades Livres } & $\begin{array}{l}\text { Actividades } \\
\text { Livres }\end{array}$ \\
\hline $\begin{array}{l}9: 30-11: 00 \\
11: 00\end{array}$ & $\begin{array}{l}\text { Expressão Plástica } \\
\text { Hora do Conto }\end{array}$ & $\begin{array}{l}\text { Apoio Escolar } \\
\text { Inglês }\end{array}$ & $\begin{array}{l}\text { Apoio Escolar } \\
\text { Expressão } \\
\text { Plástica }\end{array}$ & $\begin{array}{l}\text { Apoio Escolar } \\
(10: 45-11: 45) \\
\text { Informática } \\
\text { Jogos Variados }\end{array}$ & $\begin{array}{l}\text { Apoio Escolar } \\
\text { Yogal } \\
\text { Cul inária }\end{array}$ \\
\hline $12: 00-14: 00$ & Almoço & Almoço & Almoço & Almoço & Almoço \\
\hline $14: 30-16: 00$ & Apoio Escolar & Inglês & $\begin{array}{l}(14: 30-15: 30) \\
\text { Informática } \\
\text { Jogos Variados }\end{array}$ & Apoio Escolar & $\begin{array}{l}\text { Expressão } \\
\text { Plástica }\end{array}$ \\
\hline 16:15 & $\begin{array}{c}\text { Apoio Escolar/ } \\
\text { Ciências Divertidas }\end{array}$ & Apoio Escolar & $\begin{array}{l}\text { Apoio Escolar } \\
\text { Inglês }\end{array}$ & $\begin{array}{c}\text { Apoio Escolar } \\
\text { (16:45-17:15) } \\
\text { Música }\end{array}$ & $\begin{array}{l}\text { Yogal } \\
\text { Cul inária }\end{array}$ \\
\hline 17:15 & Hora do Conto & $\begin{array}{l}\text { (17:30-19:00) } \\
\text { Natação }\end{array}$ & $\begin{array}{l}\text { Expressão } \\
\text { Plástica }\end{array}$ & Filme & $\begin{array}{c}\text { (17:30-19:00) } \\
\text { Natação }\end{array}$ \\
\hline 18:00 - 19:00 & Actividades Livres & Actividades Livres & Actividades Livres & Actividades Livres & $\begin{array}{l}\text { Actividades } \\
\text { Livres }\end{array}$ \\
\hline
\end{tabular}


Aproveitando os tempos e os períodos não-lectivos deixados em aberto pelas escolas do $1^{\circ}$ ciclo, os CATL instituíram-se, nas últimas décadas, como "resposta social" às aludidas necessidades das famílias, propiciando não só os serviços de alimentação, transporte e acolhimento das crianças, como também o acompanhamento na realização dos trabalhos de casa (vulgo deveres) e a oferta de um leque de actividades não muito distante do espectro curricular vigente na escola básica.

O lançamento e a gradual implementação da ideia de "escola a tempo inteiro" veio, entretanto, baralhar o modo como se vinham distribuindo as possibilidades na "cidade educativa", assim como a alterar as relações tecidas no quotidiano entre os estabelecimentos de ensino do $1^{\circ}$ ciclo e as outras instituições educativas. Orientada para "a concretização do objectivo de colocar as escolas ao serviço da aprendizagem dos alunos" (cf. Relatório do Orçamento do Estado para 2006, p. 205), esta medida política acentuou ainda mais a centralidade social da instituição escolar, o que se traduziu, consequentemente, num esvaziamento das funções anteriormente acometidas àquelas instituições, exigindo delas um esforço de redefinição dos seus lugares e papéis no processo educativo das crianças e dos jovens. No fundo, as transformações em curso sugerem a tendência para a formalização do não-formal e do informal, no sentido em que as novas temporalidades do espaço escolar, alicerçadas em larga medida na gestão de novas parcerias e protocolos locais (de onde se destaca o papel central das autarquias locais), se consubstanciaram pela apropriação de actividades, de práticas e de experiências exteriores de reconhecido valor educativo.

Assalta-nos a metáfora da escola como eucalipto educativo: o enfrentamento da propalada crise da educação escolar parece querer esboçar-se efectivamente com mais escola (cf. Correia \& Matos, 2001), só que agora capitalizando e absorvendo para o seu interior algumas das iniciativas mais populares de educação não-escolar. Mesmo sendo planificadas preferencialmente com as autarquias e contando com várias entidades promotoras (autarquias locais, associações de pais e de encarregados de educação, instituições particulares de solidariedade social e os próprios agrupamentos de escolas - cf. Despacho n. $\stackrel{0}{14}$ 460/2008, de 26 de Maio), tenderá sempre a prevalecer nas actividades de enriquecimento 
curricular uma lógica centrípeta na gestão e no reforço da cultura escolar, de uma educação na e para a escola e não de uma educação com e para além da escola.

É certo que por mais actividades curriculares ou de "enriquecimento curricular" que a escola pública disponibilize, num suposto projecto educativo de qualidade, haverá sempre lugar à procura e à construção de percursos de diferenciação cultural e social. A "escola a tempo inteiro" pode, de facto, representar uma medida de democratização no acesso a aprendizagens, saberes e actividades culturais, desportivas e artísticas, que antes estavam arredadas dos espaços e dos tempos escolares e apenas preenchiam o diaa-dia de alguns grupos sociais. No entanto, questionamo-nos se o tempo excessivo de presença na escola e nos espaços usuais de actividade lectiva não subverterá a filosofia que parece estar subjacente ao projecto da "escola a tempo inteiro". Ou seja, joga-se na articulação do formal e do não-formal a construção de uma ideia de escola que possibilite o desenvolvimento de experiências e de aprendizagens significativas de elevado potencial educativo. Na sua ausência, este projecto poderá resultar numa overdose de escola, ou "o risco de hiperescolarização da vida das crianças" (Cosme \& Trindade, 2007: 17), com consequências imprevisíveis nos futuros percursos escolares dos alunos.

\section{O fora e o dentro do não-escolar... na escola}

Mas a implementação da "escola a tempo inteiro" estendeu-se a outros níveis de ensino, operacionalizando-se através de um conjunto de regras e princípios orientadores visando a organização da vida das escolas, mais especificamente a "plena ocupação dos tempos escolares" (cf. despacho $\mathrm{n}$. 17 387/2005, de 12 de Agosto). Dispensando nesta reflexão uma análise à forma e ao pormenor deste normativo, a nossa inquietação sociológica não deixa, porém, de o tomar como alavanca problematizadora para continuar a repensar a escola pública na actualidade. Um dos aspectos que no imediato dele ressalta prende-se com a imposição de novas lógicas de uso do tempo escolar, mais especificamente aquelas que formalmente se apropriam e comprimem os tempos de sociabilidades juvenis. Os períodos não-lectivos no quotidiano escolar tendem a funcionar, igualmente, como espaços de transacção cultural e simbólica entre os jovens, ou seja, os sítios que estes 
mais tendem a preferir no contexto da escola e nos quais se partilham, por entre a informalidade das relações entre pares, saberes e aprendizagens significativas. Ora, a ocupação plena dos tempos escolares, em última instância, impedirá que a expressividade juvenil se manifeste para além dos limites do sujeito enquanto aluno, assim como as demais práticas educativas situadas num plano de informalidade tenderão a desenquadrar-se das dinâmicas programadas e formalizadas de aprendizagem.

Não menos importante, nesta sequência, é a justificação para as interrogações sobre o sentido de ir e permanecer na escola, quando se pressente que o peso constrangedor da estrutura escolar tende a subjugar as performatividades juvenis (Pais, 2005: 65) e quando entre os jovens se vai cristalizando a ideia de uma instituição com um futuro volátil. E mais premente se torna o querer saber porque se adiciona ao quotidiano escolar toda uma variedade de actividades não-escolares, sem que verdadeiramente se perceba como tudo isto se sintetiza numa educação cidadã. Contrariamente ao sentido daquelas performatividades, isto é, "sinais de inquietação em relação a 'sistemas cerrados' que [lhes] ensombram o futuro" (Id. Ibid.; aspas no original), uma outra performatividade parece impor-se no quadro mais vasto das relações sociais e que na escola se vem expressando pela adopção da ideologia das competências, na construção de percursos de individualização da excelência, na ênfase conferida aos resultados da aprendizagem e no modo de regulação dos processos e das práticas educativas.

O quadro seguinte adensa ainda mais o nosso espectro problematizador. A informação nele contida provém de uma turma que frequentou o $6^{\circ}$ ano numa sede de um agrupamento de escolas no concelho de Braga, cujos resultados escolares durante $02^{\circ}$ ciclo a classificaram como a melhor turma da escola ${ }^{12}$. Os resultados finais do $2^{\circ}$ ciclo, sintetizados nas segunda e terceira colunas, mostram-nos que metade da turma se situa num nível médio a rondar o quatro (4) (Média 5), tendência esta que sobe se utilizarmos a média das sete disciplinas (Média 7). Um quarto dos alunos obteve uma média global igual ou superior a 4,6. Frequentando, predominantemente, os tempos lectivos da manhã, a grande maioria dos alunos tem origens sociais e culturais acima da média, sendo os seus progenitores enquadráveis maioritariamente nas profissões intelectuais e 
científicas e nas profissões liberais. Na composição desta turma interferiu, em grande medida, a existência de um terço dos alunos com um percurso anterior de formação musical, que lhes permitiu inscrever-se no "ensino articulado de música". Sendo-lhes permitido abdicarem de algumas disciplinas do currículo (Educação Musical, Educação Visual e Tecnológica e Educação Física substituídas pela Formação Musical, Classe de Conjunto e Instrumento), porém, estes alunos optaram pela sua frequência (à excepção da Educação Musical), o que acarretou um aumento do volume das actividades escolares e extra-escolares e consequentemente menor disponibilidade para as convivialidades e lazeres juvenis. Do levantamento que fizemos junto dos directores de turma, este grupo de alunos ostentava também o maior número de actividades extracurriculares frequentadas fora e dentro da escola.

\section{Quadro 2 - Actividades extracurriculares frequentadas por uma turma do 6 ano}

\begin{tabular}{|c|c|c|c|c|c|}
\hline \multirow[t]{2}{*}{ Aluno } & \multirow[t]{2}{*}{ Sexo } & \multirow{2}{*}{ 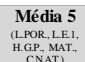 } & \multirow{2}{*}{$\begin{array}{l}\text { Média } 7 \\
\text { Mccia } 5+ \\
\text { EVT,E.HS.) }\end{array}$} & \multicolumn{2}{|c|}{ Actividades Extracurricul ares } \\
\hline & & & & $\mathrm{Na}$ Es cola & Fora da Escola \\
\hline 1 & $\mathrm{~F}$ & 5,00 & 4,57 & Música + Pintura & Natação + Dança \\
\hline 2 & M & 3,00 & 3,14 & & Catequese + Francês \\
\hline 3 & $\mathrm{~F}$ & 3,20 & 3,29 & & $\begin{array}{l}\text { Catequese } \\
\text { lations }\end{array}$ \\
\hline 4 & $\mathrm{M}$ & 3,40 & 3,57 & & Futebol + Música \\
\hline 5 & M & 3,20 & 3,43 & & Futebol + Música + Inglês \\
\hline 6 & $\mathrm{~F}$ & 5,00 & 4,86 & & Natação + Música \\
\hline 7 & M & 4,20 & 4,43 & & Futebol + Inglês \\
\hline 8 & $\mathrm{M}$ & 4,40 & 4,57 & Andebol & Futebol + Natação + Música \\
\hline 9 & M & 2,00 & 2,29 & & Catequese \\
\hline 10 & $\mathrm{M}$ & 3,60 & 3,57 & & And ebol + Música + Inglês \\
\hline 11 & M & 4,60 & 4,71 & & And ebol + Inglês \\
\hline 12 & M & 3,80 & 3,86 & & Rugby + Música \\
\hline 13 & $\mathrm{M}$ & 3,80 & 4,14 & Música & Futebol + Hóquei \\
\hline 14 & $\mathrm{~F}$ & 4,00 & 4,14 & Teatro + Pintura & Ballet + Música + Catequese \\
\hline 15 & $\mathrm{~F}$ & 4,40 & 4,43 & Voleibol + Música + Teatro + Pintura & Natação + Catequese + Dança \\
\hline 16 & M & 3,80 & 3,86 & Música & \\
\hline 17 & M & 3,20 & 3,43 & & Futebol + Música + Inglês + Catequese \\
\hline 18 & M & 4,00 & 4,00 & Música & Inglês \\
\hline 19 & $\mathrm{~F}$ & 3,40 & 3,29 & Pintura & Ballet + Música + Catequese + Inglês \\
\hline 20 & $\mathrm{~F}$ & 3,80 & 4,14 & & Natação + Ballet \\
\hline 21 & $\mathrm{~F}$ & 4,20 & 4,14 & Música + Pintura & Natação \\
\hline 22 & $\mathrm{~F}$ & 4,60 & 4,57 & & Catequese \\
\hline 23 & $\mathrm{M}$ & 5,00 & 4,86 & Música & Futebol \\
\hline 24 & M & 2,60 & 3,00 & & \\
\hline 25 & M & 5,00 & 4,86 & & Catequese + Inglês \\
\hline 26 & M & 4,60 & 4,43 & & And ebol + Natacão + Música + Inglês \\
\hline 27 & $\mathrm{M}$ & 3,00 & 3,43 & & Catequese \\
\hline 28 & $\mathrm{M}$ & 4,80 & 4,43 & & Catequese + Inglês \\
\hline 29 & M & 3,40 & 3,71 & & Futebol + Músca \\
\hline
\end{tabular}

Legenda: Média 5 - resulta da média aritmética obtida a partir das classificações finais atribuídas a Língua Portuguesa, Língua Inglesa, História e Geografia de Portugal, Matemática e Ciências da Natureza. A Média 7, para além destas disciplinas, incorpora a Educação Visual e Tecnológica e Educação Física. A actividade Música, fora da escola, corresponde à frequência do regime articulado, constituído pelas seguintes componentes lectivas: Formação Musical, Classe de Conjunto e Instrumento. 
A frequência de actividades extra-curriculares no espaço escolar tende a constituir uma prática mais característica das raparigas, concentrando-se os rapazes, predominantemente, no exterior. Aqui o desporto e a actividade física aparecem destacados nas rotinas dos alunos, observando-se entre os rapazes uma preferência pelas modalidades colectivas (futebol e andebol) e as raparigas pela natação. A frequência de escolas especializadas de línguas (essencialmente a língua inglesa) bem como a catequese, representam contextos externos de educação e aprendizagem não-formais de um número considerável de alunos, ambos articulando-se e complementando-se com as lógicas curriculares prevalecentes no interior da escola. Perante a evidência dos dados, uma vez mais sublinhamos a ideia de escola interceptada por múltiplas lógicas e racionalidades educativas, um "entreposto cultural" onde se entrecruzam o escolar e o não-escolar, o que the confere um carácter simultaneamente híbrido e holístico.

Mas estes dados não deixam de igual modo de nos inquietar, não tanto pela clareza da informação, mas pela agenda investigativa que comporta e suas correlativas interrogações (ainda) sem resposta: não sendo visível, numa primeira leitura, uma relação entre os resultados escolares e a frequência de actividades extracurriculares destes alunos, haverá então algum quadro explicativo onde estas duas variáveis se associem para dar sentido a essa eventual relação? Que variáveis se interporão entre a constatação de bons resultados escolares e a grande variedade de modalidades não-formais frequentadas? Numa turma onde se denota alguma homogeneidade cultural e social, como interpretar a gestão diferenciada dos interesses e dos recursos educativos no quotidiano dos alunos? Qual a autonomia decisória dos jovens na escolha das opções não-escolares e como é que isto se articula com as culturas e identidades juvenis? Propiciará a escola articulações profícuas entre as experiências escolares e as nãoescolares, ou tal desiderato estará apenas inscrito nos projectos e nos "contextos subjectivos e trajectivos" (Pais, 2005: 65) dos jovens? Que predisposições estarão implícitas no investimento em modalidades nãoformais, quando o debate sobre a "crise" da escola reactualiza, a cada passo, a inevitável importância das componentes tradicionais do currículo? Estarão as actividades extracurriculares mais subjugadas a lógicas educativas ou meramente a lógicas de ocupação dos tempos livres, coincidentes com o horário laboral dos familiares? 
Uma resposta sustentada a estas questões carece ainda de um agendamento e ultrapassa certamente o âmbito desta reflexão. Porém, o estudo das relações entre o escolar e o não-escolar não pode prescindir de um olhar sociológico que incida sobre os seus efeitos numa óptica de democratização social, pois a combinação estratégica e diferencial entre ambos os subcampos, desenvolvida sobretudo pelas famílias, poderá potenciar, a médio prazo, a expressão de novas formas de desigualdade educativa e cultural, que a instituição escolar não conseguirá contrariar com medidas do tipo "escola a tempo inteiro" e "ocupação plena dos tempos escolares". O reconhecimento da educação na transversalidade das múltiplas experiências de vida do sujeito, enfatiza, igualmente, a necessidade de uma redobrada atenção sobre um objecto que quotidianamente se molda, flui e escapa aos actuais espaços-tempo da escola, o que significa, em última instância, partir para a compreensão dos sentidos que emergem e se actualizam na relação entre actores e instituições sociais e educativas.

\section{Notas}

* Trabalho desenvolvido no Centro de Investigação em Educação (CIEd) da Universidade do Minho.

1 Pelos Despachos nos 16 795/2005, de 3 de Agosto (alargamento do horário das escolas do $1^{\circ}$ ciclo), e 17 385/2005, de 12 de Agosto (ocupação dos tempos escolares), promulgaram-se as orientações constitutivas do projecto político da "escola a tempo inteiro". Todavia, face ao suposto "sucesso" na generalização do Ensino do Inglês nos 3. e 4. anos do 1. ciclo do ensino básico (Despacho nำ14 $753 / 2005$, de 5 de Julho), é o próprio Ministério da Educação a reiterar que este programa "assume claramente o papel de primeira medida efectiva de concretização de projectos de enriquecimento curricular e de implementação do conceito de escola a tempo inteiro" (cf. Despacho no 12 591/2006, de 16 de Junho). No fundo, este "conceito" remete-nos para "a ocupação educativa dos alunos, de forma plena, ao longo do tempo escolar e no espaço escolar" (Pires, 2007: 78). Sobre este assunto veja também o ensaio de Cosme \& Trindade (2007).

2 Refira-se que o autor também sublinha que esta predisposição em relação à "educação não-formal" não é uniforme em todos os contextos em que a mesma foi experienciada, observando-se inclusivamente a situação oposta: "that the concepts which lie behind the word 'formal' in education are the enemy, and that 'non-formal' is the celebration of liberation, throwing off the shackles of formality which have for so long prevented education from being education" (Rogers, 2004: 4; aspas no original). 
3 Segundo Bhola (1983: 49), a preocupação subjacente à expressão de educação não-formal encontra eco noutras fórmulas precedentes, tais como: "éducation de base, éducation fondamentale, alphabétisation fontionnelle, éducation de adultes, éducation extrascolaire, éducation de la deuxième chance, formation continue, éducation récurrente, éducation parascolaire et éducation permanente". Igualmente Radcliffe \& Colletta (1989: 1838) sustentam que "en los años 50, los informes de la UNESCO trataban sobre los mismos temas en términos de 'desarrollo comunitario y educación de la comunidad' y hablaban de 'alfabetización funcional' en los años 70" (aspas no original). Sobre a reduzida popularidade da expressão de educação não-formal nos países ditos desenvolvidos, não deixa de ser significativa a constatação de Smith (1996): "In many northen countries the notion of non-formal education is not common in internal policy debates - preferred alternatives being community education and community learning, informal education and social pedagogy".

4 Socorrendo-se de um estudo publicado no final da década passada por Roger Boshier sobre o relatório Faure, Licínio Lima (2003: 131) sugere que a ambiguidade sobre o uso indiferenciado destas noções, tanto ali como agora, constitui afinal um desafio que ainda não se logrou ultrapassar: "[Boshier] chama a atenção para o facto de o conceito central ali adoptado resultar de uma resposta ao 'fermento' dos anos 60 e ainda para o uso dos conceitos de educação e de aprendizagem praticamente como sinónimos, seja ao longo do livro, seja ainda hoje em muitos lugares do mundo" (aspas no original).

5 Debruçando-se sobre a emergência no seio da UNESCO de uma nova orientação designada de educação permanente, Moacir Gadotti (1995: 271) concluiu que "esse novo conceito da educação era extremamente amplo, mas era em sua essência uma educação para a paz. Depois de mais de meio século de guerras mundiais, a todos parecia necessário que a educação fosse um baluarte da paz" (itálico no original).

6 Como explicitam Bourdieu \& Passeron (1990): "Le privilège culturel est manifesté lorsqu'il s'agit de la familiarité avec les oeuvres que seule peut donner la fréquentation régulière du théâtre, du musée ou du concert (fréquentation qui n'est pas organisée par l'École, ou seulement de façon sporadique)".

7 Interrogando-se sobre a validade do pressuposto da neutralidade educativa, Paulo Freire (1972: 194) pôs as questões nestes termos: "Nous déclarons que l'éducation est neutre, comme si elle n'était pas une obligation humaine, comme si les hommes n'étaient pas êtres insérés dans l'histoire, comme si le caractère téléologique de la praxis pédagogique n'était pas le facteur qui rend sa neutralité impossible".

8 Para Paulo Freire (2002: 58) "a educação se torna um ato de depositar, em que os educandos são os depositários e o educador o depositante. Em lugar de comunicarse, o educador faz 'comunicados' e depósitos que os educando, meras incidências, recebem pacientemente, memorizam e repetem" (aspas no original). Para Lima (1999: 34), a crítica de Paulo Freire à "educação bancária" "representa um dos mais violentos e eloquentes ataques à organização burocrática e à racionalidade técnicoinstrumental em educação".

9 Neste documento o termo não-formal aparece dezassete vezes associado a noção de aprendizagem e apenas duas vezes relacionado com a noção de educação. 
Numa comunicação subsequente da Comissão, intitulada Tornar o Espaço Europeu de Aprendizagem ao Longo da Vida uma Realidade, saída em 2001, enquanto que a aprendizagem não-formal é utilizada trinta e sete vezes a educação não-formal apenas é referida uma única vez.

10 De entre as principais referências normativas que configuram as actuais políticas públicas para a escola do $1^{\circ}$ ciclo salienta-se: o Despacho ํำ14 753/2005, de 5 de Julho - criação do programa de generalização do ensino de inglês nos $3^{\circ}$ e $4^{\circ}$ anos do $1^{\circ}$ ciclo do ensino básico; o Despacho no 16 795/2005, de 3 de Agosto — define "as normas a observar no período de funcionamento" dos estabelecimentos de educação pré-escolar e 1. ciclo do ensino básico; o Despacho no 12 591/2006 de 16 de Junho e o Despacho no 14 460/2008 de 26 de Maio - definem as "normas a observar no período de funcionamento dos respectivos estabelecimentos de ensino bem como a oferta das actividades de enriquecimento curricular e de animação e apoio à família".

11 Sobre o trabalho escolar dos alunos para além da escola, no que se reporta à realidade francesa, consultar Glasman (1992), Glasman \& Besson (2004). Recentemente, sobre a realidade portuguesa, sublinhamos a pesquisa de Costa, Neto-Mendes \& Ventura (2008).

12 Se considerarmos as oito turmas do $6^{\circ}$ ano existentes na escola, esta turma apenas não foi a melhor a Língua Portuguesa e a Educação Física. Entretanto, os resultados das Provas de Aferição do ano lectivo de 2008/2009 vieram reforçar este cenário, destacando-se no maior número de níveis $\mathrm{A}$ a Língua Portuguesa e a Matemática: dos catorze alunos que obtiveram simultaneamente o nível $A$ às duas disciplinas, oito pertenciam a esta turma.

\section{Referências}

AFONSO, Almerindo J. (1998). Políticas Educativas e Avaliação Educacional. Para uma Análise Sociológica da Reforma Educativa em Portugal (1985-1995). Braga: Universidade do Minho/IEP/CEEP.

AFONSO, Almerindo J. (2001). Os lugares da educação. In Olga R. von Simson, Margareth B. Park \& Renata S. Fernandes (Orgs.), Educação Não-formal. Cenários da Criação. Campinas: Editora da Unicamp, pp. 29-38.

AFONSO, Almerindo J. (2003). A sociologia da educação e os contextos e processos educativos não-escolares. Educação \& Linguagem, nำ 8, pp. 35-44.

AHMED, Manzoor (1983). Le non-formel et les questions critiques de l'éducation. Perspectives, vol. XIII, no1, pp. 37-47.

APPLE, Michael W. (2003). A extinção dos professores: A política cultural do ensino em casa. In Jurjo Torres Santomé, João M. Paraskeva \& Michael W. Apple, Ventos de Desescolarização. A Nova Ameaça à Escolarização Pública. Lisboa: Plátano Editora, pp. 116-141.

BERNSTEIN, Basil (2001). Das pedagogias aos conhecimentos. Educação, Sociedade \& Culturas, $\mathrm{n}^{\circ}$ 15, pp. 9-17. 
BHOLA, H. S. (1983). La educación no formal en perspectiva. Perspectives, vol. XIII, no1, pp. 45-54.

BOURDIEU, Pierre (1979). La Distinction. Critique Social du Jugement. Paris: Les Éditions de Minuit.

BOURDIEU, Pierre \& PASSERON, Jean-Claude (s/d). A Reprodução. Elementos para uma Teoria do Sistema de Ensino. Lisboa: Editorial Vega.

BOURDIEU. Pierre \& PASSERON, Jean-Claude (1990). Les Héritiers. Les Étudiants et la Culture. Paris: Les Éditions de Minuit.

BREMBECK, Cole S. (1976). Introducción. In Cole S. Brembeck \& Timothy J.Thompson (Eds.) (1976), Nuevas Estrategias para el Desarrollo Educativo: Investigación Intercultural de Alternativas no Formales. Buenos Aires: Editorial Guadalupe, pp. 9-16.

CANÁRIO, Rui (2002). Escola - crise ou mutação? In AA.VV., Espaços de Educação. Tempos de Formação. Lisboa: Fundação Calouste Gulbenkian, pp. 141-151.

CANÁRIO, Rui (2005). O que é a Escola? Um "Olhar" Sociológico. Porto: Porto Editora.

CANÁRIO, Rui (2006). Aprender sem ser ensinado. A importância estratégica da educação não formal. In Licínio C. Lima, José A. Pacheco, Manuela Esteves \& Rui Canário, A Educação em Portugal (1986-2006). Alguns Contributos de Investigação. Lisboa: Sociedade Portuguesa de Ciências da Educação, pp. 155-200. [em linha] [acedido em 29 de Janeiro de 2007, disponível em http://www.debatereducacao.pt/index.php?option=com_docman\&task=cat_view \&gid=20\&ltemid $=10$ ]

COMISSÃO DAS COMUNIDADES EUROPEIAS (2000). Memorando sobre a Aprendizagem ao Longo da Vida. Documento de trabalho dos serviços da Comissão, SEC (2000) 1832. Bruxelas: CCE.

COOMBS, Philip H. (1968). La Crise Mondiale de l'Éducation. Une Analyse de Systèmes. Paris: PUF.

COOMBS, Philip H. (1973). Faut-il développer l'éducation périscolaire? Perspectives, Vol. III, 꾸, pp. 315-338.

COOMBS, PHilip H. (1985). La Crisis Mundial en la Educación. Perspectivas Actuales. Madrid: Santillana.

COOMBS, Philip H., PROSSER, Roy C. \& AHMED, Manzoor (1973). New Paths to Learning for Rural Children and Youth. New York: International Council for Educational Develepment.

COOMBS, Philip H. \& AHMED, Manzoor (1975). La Lucha Contra la Pobreza Rural. El Aporte de la Educación no Formal. Madrid: Editorial Tecnos.

CORREIA, José A. (1998). Para uma Teoria Crítica em Educação. Porto: Porto Editora.

CORREIA, José A., MATOS, Manuel (2001). Da crise da escola ao escolocentrismo. In Stephen R. Stoer, Luíza Cortesão e José A. Correia (orgs.), Transnacionalização da Educação. Da Crise da Educação à Educação da Crise. Porto Afrontamento, pp. 91-117.

COSME, Ariana \& TRINDADE, Rui (2007). Escola a Tempo Inteiro. Escola para que te Quero? Porto: Profedições. 
COSTA, Jorge A.; NETO-MENDES, António \& VENTURA, Alexandre (2008). Xplika: Investigação sobre o Mercado das Explicações. Aveiro: Universidade de Aveiro

DANDURAND, Pierre, OLLIVIER, Émile (1991). Centralité des savoirs et éducation: Vers de nouvelles problématiques. Sociologie et Sociétés, Vol. XXIII, nำ1, pp. 323.

DUBET, François (2002). Le Déclin de l'Institution. Paris: Seuil.

DUBET, François \& MARTUCELLI, Danilo (1996). A l'École. Sociologie de l'Expérience Scolaire. Paris: Seuil.

FAURE, Edgar, HERRERA, Felipe, KADDOURA, Abdul-Razzak, LOPES, Henri, PETROVSKI, Arthur, RAHNEMA, Majid \& WARD, Frederick (1973). Aprender a Ser. La Educación del Futuro. Madrid: Alianza Editorial / UNESCO.

FREIRE, Paulo (1972). L'éducation: Domestication ou libération? Perspectives, vol. II, ํㅡ, pp. 193-202.

FREIRE, Paulo (1976). L'alphabétisation et le 'rêve possible'. Perspectives, vol. VI, no2, pp. 70-73.

FREIRE, Paulo (2002). Pedagogia do Oprimido. São Paulo: Editora Paz e Terra (32 edição).

GADOTTI, Moacir (1995). História das Ideias Pedagógicas. São Paulo: Editora Ática (3 $3^{\underline{a}}$ edição).

GLASMAN, Dominique (1992). L'École Hors l'École. Soutien Scolaire et Quartiers. Paris: ESF éditeur.

GLASMAN, Dominique \& BESSON, Leslie (colab.) (2004). Le Travail des Élèves pour l'École en Dehors de l'École. Rapport établi à la demande du Haut conseil de l'évaluation de l'école. № 15, Décembre [em linha]. [acedido em 4 de Novembro de 2005, disponível em http://cisad.adc.education.fr/hcee/documents/ rapport_Glasman_Besson.pdf]

GRANDSTAFF, Marvin (1976). Nonformal education: Some indications for use. Comparative Education Review, vol. 20, №3, pp. 294-304.

HUSÉN, Torsten (1982). Tendances actuelles de l'éducation. Perspectives, vol. XII, nำ1, pp. $47-58$

ILLICH, Ivan (1973). Inverter as Instituições. Lisboa: Moraes Editores.

ILLICH, Ivan (1976). Aprender sem escola. In Ivan Illich, Hans Friemond, Walter Dirks, Günther Nenning \& Werner Simpfendörfer, A Escola e a Repressão dos Nossos Filhos. Lisboa: Publicações Europa-América, pp. 11-60.

ILLICH, Ivan (1988). Sociedade Sem Escola. Petrópolis: Vozes (8 $8^{\underline{a}}$ edição).

LA BELLE, Thomas J. (1981). An Introduction to the nonformal education of children and youth. Comparative Education Review, vol. 25, n3, pp. 313-329.

LA BELLE, Thomas J. (1982). Formal, nonformal and informal education: A holistic perspective on lifelong learning. International Review of Education, vol. XXVIII, n으, pp. 158-175.

LA BELLE, Thomas J. \& VERHINE, Robert E. (1975a). Education, social change, and social stratification. In Thomas J. La Bellle (Ed.), Educational Alternatives in Latin Americ. Los Angeles: UCLA Latin American Center Publications, pp. 3-71. 
LA BELLE, Thomas J. \& VERHINE, Robert E. (1975b). Nonformal education and ocupational stratfication: Implications for Latina America. Harvard Educational Review, no45, pp. 160-191.

LIMA, Licínio C. (1999). Organização Escolar e Democracia Radical. Paulo Freire e a Governação Democrática da Escola Pública. São Paulo: Cortez: Instituto Paulo Freire.

LIMA, Licínio C. (2003). Formação e aprendizagem ao longo da vida: entre a mão direita e a mão esquerda de Miró. In AA.VV., Cruzamento de Saberes, Aprendizagens Sustentáveis. Lisboa: F. C. Gulbenkian, pp. 129-148.

LIMA, Licínio C. (2006). Introdução. In Licínio C. Lima (Org.), Educação Não Escolar de Adultos: Iniciativas de Educação e Formação em Contexto Associativo. Braga: Universidade do Minho/Unidade de Educação de Adultos, pp. 15-22.

LIMA, Licínio C. (2007). Educação ao Longo da Vida. Entre a Mão Direita e a Mão Esquerda de Miró. São Paulo: Cortez Editora.

LIMA, Licínio C. (2009). A educação faz tudo? Crítica do pedagogismo na "sociedade da aprendizagem". Oração de Sapiência proferida na Universidade do Minho a 17 de Fevereiro de 2009 (texto policopiado).

NÓVOA, António (2006). Conferência de abertura do debate nacional sobre educação, proferida na Assembleia da República em 22 de Maio de 2006. [em linha] [Acedido em 14 de Junho de 2006, disponível em http:// www.debatereducacao.pt/index.php?option=com_docman\&task=cat_view\&gid $=18 \&$ Itemid $=10]$

PAIN, Abraham (1990). Éducation Informelle. Les Effets Formateurs dans le Quotidien. Paris: Éditions L'Harmattan.

PAIS, José M. (2005). Jovens e cidadania. Sociologia, Problemas e Práticas, n49, pp. 53-70.

PALHARES, José A. (2008). Os sítios de educação e socialização juvenis. Experiências e representações num contexto não-escolar. Educação, Sociedade \& Culturas, ํㅡㄴ 27, pp. 109-130.

PALHARES, José A. (2007). Um olhar retrospectivo sobre a educação não-formal: A institucionalização, as dinâmicas e as reconfigurações actuais de um subcampo educativo. In AA.VV. (Eds.), Actas do XIV Colóquio AFIRSE — Para um Balanço da Investigação em Educação de 1960 a 2005. Teorias e Práticas. Lisboa: Educa / Unidade de I \& D de Ciências da Educação, CD-ROM.

PAULSTON, Rolland G. (ed.) (1972). Non-formal Education: An Annotated International Bibliography. New York/London: Praeger Publishers.

PIRES, Carlos (2007). A construção de sentidos em política educativa: O caso da Escola a Tempo Inteiro. Sísifo. Revista de Ciências da Educação, no 4, pp. 7786 [em linha]. [Acedido em 15 de Março de 2008, disponível em http://sisifo.fpce.ul.pt].

POIZAT, Denis (2003). L'Éducation non Formelle. Paris: L'Harmattan.

QUINTANA CABANAS, José M. (1976). La educación informal y la escuela en la sociedad del futuro. Revista de Ciências de la Educación, Ano XXII, nํ85, pp. 17-29. 
RADCLIFFE, D. J., COLLETA, N. J. (1989). Educación no Formal. In Torsten Husén \& Neville Postlethwaite (Dir.), Enciclopedia Internacional de la Educación, vol. 3. Barcelona: Ministerio de Educación y Ciencia / Editorial Vicens-Vives, pp. 18371842.

REIMER, Everett (1976). La Escuela ha Muerto: Alternativas en Materia de Educación. Barcelona: Barral Editores.

ROGERS, Alan (2004). Non-formal Education. Flexible Schooling or Participatory Education?. Hong Kong: Kluwer Academic Publishers.

SMITH, Mark K. (1996). Non-formal Education. In Infed - The Encyclopaedia of Informal Education. [em linha]. [Acedido em 3 Novembro de 2003, disponível em http://www.infed.org/biblio/b-nonfor.htm].

TORRES, Leonor L. (2008). A escola como entreposto cultural: o cultural e o simbólico no desenvolvimento democrático da escola. Revista Portuguesa de Educação, vol. 21, n-1, pp. 59-81

TORRES SANTOMÉ, Jurjo (2003). Escola e família: Duas instituições em confronto?. In Jurjo Torres Santomé, João M. Paraskeva e Michael W. Apple, Ventos de Desescolarização. A Nova Ameaça à Escolarização Pública. Lisboa: Plátano Editora, pp. 15-56.

TOURAINE, Alain (1998). Iguais e Diferentes. Poderemos Viver Juntos? Lisboa: Instituto Piaget.

TRILLA BERNET, Jaume (1998). La Educación Fuera de la Escuela. Ámbitos no Formales y Educación Social. Barcelona: Ariel (3ª edição).

VINCENT, Guy; LAHIRE, Bernard \& THIN, Daniel (1994). Sur L’histoire et la théorie de la forme scolaire. In Guy Vincent (Dir.), L'éducation Prisonnière de la Forme Scolaire? Lyon: Presses Universitaires de Lyon, pp. 11-48. 


\title{
REFLECTIONS ON THE NON-SCHOOL IN THE SCHOOL AND BEYOND
}

\begin{abstract}
Assuming that the public school is in a state of transformation, particularly in regard to a (re) definition of its social functions and its expression in structuring the daily lives of children and young people, we commence this reflection nourished by the conviction that it is possible to comprehend it by taking a critical stroll between their borders and at the same time establishing lines of analysis on the relationships that this institution establishes with other educational instances. The implementation of policy measures such as "full time school" appears in this text as a lever to reflective thinking about educational opportunities that may be drafted between the school and the nonschool, both in school space and time and beyond them. We will also discuss the growing centrality of school culture in the construction and definition of pathways, strategies and experiences of education (non-formal and informal) in distinct areas of the life of students.
\end{abstract}

Keywords

School education and non-school education (non-formal and informal);

Educational pathways; Full time school; Educational peripheries 


\section{RÉFLEXIONS SUR LE NON-SCOLAIRE À L'ÉCOLE ET EN-DEHORS DE L’ÉCOLE}

\section{Résumé}

Admettant que l'école publique est en transformation, particulièrement en ce qui concerne la (re)définition de ses fonctions sociales et de son expression dans la structuration du quotidien des enfants et des jeunes, nous partons vers cette réflexion alimentés par la conviction qu'il est possible de la comprendre par la déambulation critique entre ses frontières. Nous prétendons en même temps établir des pistes d'analyse par rapport aux relations que cette institution établit avec d'autres instances éducatives. La mise en place de mesures politiques comme l'"école à temps complet" surgit dans ce contexte comme le levier réflexif pour penser aux possibilités éducatives qui s'ébauchent entre le scolaire et le non-scolaire, aussi bien dans les espaces et temps scolaires qu'en dehors d'eux. Nous ne cesserons pas non plus de problématiser la croissante centralité de la culture scolaire dans la construction et dans la définition de parcours, de stratégies et d'expériences d'éducation (non formelles et informelles) dans les différents cadres de vie des élèves.

Mots-clé

Éducation scolaire et éducation non-scolaire (non-formelle et informelle); Parcours éducatifs; École à temps complet; Périphéries éducatives.

Recebido em Junho/2009

Aceite para publicação em Setembro/2009

\footnotetext{
Toda a correspondência relativa a este artigo deve ser enviada para: José Augusto Palhares, Instituto de Educação, Universidade do Minho, Campus de Gualtar, 4710-057 Braga, Portugal. Telef.: 253 604623/604279; e-mail: jpalhares@iep.uminho.pt
} 